\title{
Azlocillin compared with carbenicillin in the treatment of bronchopulmonary infection due to Pseudomonas aeruginosa in cystic fibrosis
}

\author{
ARL PENKETH, MARGARET E HODSON, H GAYA, JC BATTEN \\ From the Cardiothoracic Institute, Brompton Hospital, London
}

ABSTRACT A randomised controlled open comparison of azlocillin and gentamicin versus carbenicillin and gentamicin was carried out in patients with cystic fibrosis who were chronically infected with Pseudomonas aeruginosa. The clinical response was assessed by measurements of pulmonary function and of the patients' feelings of wellbeing scored on a visual analogue scale. The sputum penetration of the antibiotics used was also studied. The two groups of 10 patients were similar in terms of age, sex, and pulmonary function at entry to the trial. Both regimens produced significant improvement in pulmonary function over 10 days. The mean $\mathrm{FEV}_{1}$ in the azlocillin group increased from 1206 to $1760 \mathrm{ml}(\mathrm{p}<0.001)$. In the carbenicillin group the mean $\mathrm{FEV}_{1}$ increased from 1116 to $1619 \mathrm{ml}(\mathrm{p}<0.001)$. Significant improvements in peak expiratory flow rate, forced vital capacity, and score on the visual analogue scale were also seen but there was no significant difference between the antibiotic regimens. Despite high serum concentrations the sputum penetration of the antibiotics was poor.

The major factor contributing to morbidity and mortality in cystic fibrosis is progressive pulmonary disease. ${ }^{2}$ The dominant pathogen in older patients is now Pseudomonas aeruginosa, and no antibiotic regimen has yet achieved more than a transient eradication or suppression of this organism in cystic fibrosis patients' sputum. ${ }^{3}$

Within a given group of patients with cystic fibrosis, those without pseudomonas infection are in better general condition than those harbouring the organism; and there is an association between pseudomonas infection and the severity of pulmonary disease. ${ }^{14}$ In a recent longitudinal study pseudomonas infection was the only factor significantly associated with a deterioration in the condition of an individual patient with time..$^{5}$ For these reasons cystic fibrosis patients colonised by pseudomonas who experience an acute exacerbation of their respiratory symptoms are treated with courses of antibiotics directed against pseudomonas, despite the lack of good scientific evidence that specific antipseudomonal chemotherapy is beneficial. $^{3}$ Address for reprint requests: Dr ARL Penketh, Cardiothoracic
Institute, Brompton Hospital, London SW3 6HP.

Accepted 29 November 1983
Azlocillin is a semisynthetic acylureido penicillin with a high in vitro activity against pseudomonas. It has a lower sodium content than some other semisynthetic penicillins, which may be an advantage in patients with cor pulmonale. In this study azlocillin and gentamicin were compared with carbenicillin and gentamicin in patients with cystic fibrosis infected with $P$ aeruginosa.

\section{Methods}

\section{PATIENTS AND TREATMENT}

Twenty adults with a proved diagnosis of cystic fibrosis admitted to hospital consecutively with acute exacerbations of respiratory symptoms, increasing volumes of purulent sputum, and deterioration in lung function were studied. Peak expiratory flow rate (PEFR), $\mathrm{FEV}_{1}$, and forced vital capacity (FVC) were measured on admission and patients were included if these showed a fall of at least $20 \%$ below outpatient values. Patients with severe disease, defined as $\mathrm{FEV}_{1}$ of $<20 \%$ of predicted normal values, ${ }^{6}$ were excluded. All patients had had persistent $P$ aeruginosa in their sputum for at least six months before the study. Patients with a history of penicillin allergy, appreciable liver disease, or cor pulmonale and those with organisms resistant to 
azlocillin or carbenicillin were excluded. In a single blind study, patients were randomly allocated to carbenicillin or azlocillin groups, and all patients received gentamicin intravenously eight hourly, the dose being adjusted to give a serum concentration of 8-10 $\mu \mathrm{g} / \mathrm{ml} 15$ minutes after a bolus injection. The dose of azlocillin was $5 \mathrm{~g}$ eight hourly and of carbenicillin $5 \mathrm{~g}$ six hourly. Both were given by slow intravenous infusion over 20 minutes, and all treatments were given for an arbitrary period of 10 days.

All patients received physiotherapy with postural drainage four times daily. Those with a proved reversible element of airflow obstruction received bronchodilators. Patients with other pathogens in the initial sputum culture received appropriate oral chemotherapy.

\section{CLINICAL ASSESSMENT}

Patients were assessed and examined on the first and last day of treatment by the same physician. PEFR was recorded on a Wright peak flow meter, and $\mathrm{FEV}_{1}$ and FVC were recorded on a Vitalograph spirometer. A subjective assessment of patients' wellbeing was scored on a $10 \mathrm{~cm}$ visual analogue scale. Patients were asked to mark their present position on the scale by comparison with the worst that they had ever felt $(0)$ and the best that they had felt in the previous 12 months (10). Full blood counts and erythrocyte sedimentation rates were determined and liver function tests and urea and electrolyte measurements performed to monitor toxicity.

\section{MICROBIOLOGY}

Sputum cultures were made on the first and last day of treatment. All organisms isolated were tested for antibiotic sensitivity by the Stoke's comparative disc method. ${ }^{7}$ Isolates of $\boldsymbol{P}$ aeruginosa were typed by $\mathrm{O}$ serology at the Central Public Health Laboratory, Colindale. Minimal inhibitory concentrations (MIC) and minimal bactericidal concentrations (MBC) of the three antibiotics were determined for each strain of $P$ aeruginosa by conventional broth dilution methods. ${ }^{\mathbf{8}}$ Dilutions were performed in microtitre trays with Iso-sensitest broth (Oxoid), the size of the inoculum being adjusted to give a final concentration of $10^{4}-10^{6}$ organisms $/ \mathrm{ml}$. Concentrations of the penicillin in serum and sputum were measured on the third day of treatment in all patients in the azlocillin group and seven of the carbenicillin group. Serum concentrations were measured 15 minutes after the end of the infusion and just before the next dose (six hours after carbenicillin and eight hours after azlocillin). Sputum concentrations were measured one and two hours after completion of the infusion and just before the next dose.
AZLOCILLIN AND CARBENICILLIN ASSAYS

Serum samples Serum azlocillin and carbenicillin assays were performed by bioassay after pretreatment of the serum with a resin to remove any gentamicin present. One millilitre of serum was added to $100 \mathrm{mg}$ of Dowex $50-\mathrm{X} 8$ resin (British Drug Houses) and mixed on a rotator for 15 minutes. The resin was allowed to settle by letting it stand for a further five minutes and the supernatant serum was removed. The bioassays for azlocillin and for carbenicillin were performed on DST agar (Oxoid) with $P$ aeruginosa (National Collection of Type Cultures 10701) as the indicator organism. Standards of $2.5-40 \mu \mathrm{g} / \mathrm{ml}$ were prepared for both antibiotics in horse serum (No 3 Wellcome) and resin absorbed test sera were appropriately diluted in serum in order to bring them within the concentrations of the standard curve range. After incubation for 18 hours at $37^{\circ} \mathrm{C}$, inhibition zone diameters were measured with a zone projector (Leebrook Instruments). Derandomisation and calculation of the results were performed according to the method of Perkins. ${ }^{9}$

Sputum samples Sputum was homogenised by vigorous agitation on a vortex mixer in a bottle containing six $5.5 \mathrm{~mm}$ glass beads. The homogenates were then treated in the same way as serum samples.

\section{STATISTICS}

Baseline data on the two groups of patients on entry to the study were compared with Wilcoxon's rank sum test. The improvements in respiratory function with the two treatments were compared with an analysis of covariance.

\section{Results}

\section{RESPIRATORY FUNCTION}

There was no significant difference between the two groups of patients on entry to the trial (table 1). Both antibiotic regimens produced a significant improvement in PEFR, FEV , and FVC of $41-46 \%$ of baseline values, but there was no difference between the two treatments (table 2).

\section{TOXICITY}

Both regimens were well tolerated and there was no evidence of toxicity.

\section{PATIENTS' ASSESSMENT}

All patients considered themselves to have improved with the treatment. In the azlocillin group the mean (1 SD) score on the analogue scale on day 0 was $4.28(1.19)$, improving to $8.67(1.42)$ on day $10(\mathrm{p}<0.001)$. In the carbenicillin group the mean score on day 0 was $3.54(1.78)$, improving to 8.23 
Table 1 Data on patients on entry to the study

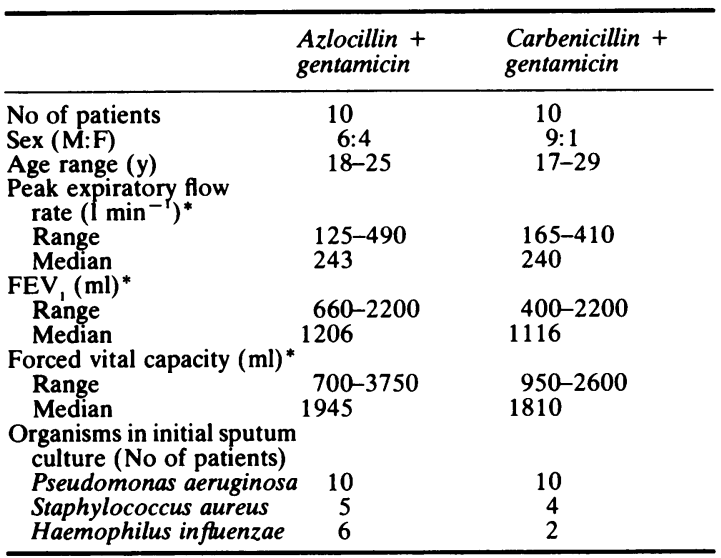

*There was no significant difference between the two groups in the lung function variables.

(1.08) on day $10(\mathrm{p}<0.001)$. There was no significant difference between the two groups in mean baseline score or final score.

\section{BACTERIOLOGY}

$P$ aeruginosa was isolated from the initial sputum culture in all patients but was not present in the culture taken after 10 days' treatment in two patients in the azlocillin group and one in the carbenicillin group. Follow up cultures at one month showed that the organism had reappeared in all cases. Resistance to penicillins on disc testing developed in several pseudomonas cultures in both groups of patients by day 10 , but organisms had reverted to full sensitivity by the one month follow up.

The other sputum pathogens isolated on day 0 are shown in table 1 . In the carbenicillin group samples from four patients grew Staphylococcus aureus; in two this was a heavy growth and oral flucloxacillin was given. The two individuals with Haemophilus influenzae in sputum were treated with oral amoxycillin. In the azlocillin group five patients had $S$ aureus in sputum and two were treated with oral flucloxacillin. $H$ influenzae was isolated in six patients, and all received oral amoxycillin.

\section{FOLLOW UP}

One patient in the azlocillin group did not improve sufficiently to be discharged from hospital and later died. Since the trial was completed 10 patients have been readmitted-five from the azlocillin group, an average of four months after treatment, and five from the carbenicillin group, an average of 3.6 months after treatment. This difference is not significant. The remaining nine patients are well five to 12 months after treatment.

\section{ANTIBIOTIC CONCENTRATIONS}

Antibiotic concentrations in serum and sputum are shown in table 3. Azlocillin was detected in the sputum in five out of 10 patients, the concentrations ranging from 2.4 to $13.8 \mu \mathrm{g} / \mathrm{ml}$. Carbenicillin was detected in the sputum of all seven patients tested, the concentrations ranging from 2.9 to $12.2 \mu \mathrm{g} / \mathrm{ml}$. All sputum concentrations were extremely low compared with serum values. Azlocillin gave higher serum concentrations than carbenicillin despite the longer interval between doses. Gentamicin was detectable in the sputum of only four individuals; the mean concentration at 1 hour was $1.28 \mu \mathrm{g} / \mathrm{ml}$.

\section{ANTIBIOTIC SENSITIVITY TO P AERUGINOSA}

Distinct strains of $P$ aeruginosa were isolated from the pretreatment sputum samples from 12 patients, and from post-treatment samples from five of these 12 patients. These strains were serotyped at the reference laboratory. Strains from the remaining

Table 2 Respiratory function data: mean values for the 10 patients in each group with standard deviation in parentheses

\begin{tabular}{|c|c|c|c|c|}
\hline Treatment group & Day 0 & Day 10 & $\begin{array}{l}\text { \% improvement on } \\
\text { treatment and } \\
\text { significance }(p)^{*}\end{array}$ & $\begin{array}{l}\text { Difference between two } \\
\text { treatments* }\end{array}$ \\
\hline $\begin{array}{l}\text { PEFR }\left(1 \mathrm{~min}^{-1}\right) \\
\text { Azlocillin }\end{array}$ & $243.0(108)$ & $343 \cdot 5(127)$ & $41.4(<0.001)$ & \multirow{2}{*}{ NS } \\
\hline Carbenicillin & $266 \cdot 6(77)$ & $376.2(94.4)$ & $41 \cdot 1(<0 \cdot 001)$ & \\
\hline $\begin{array}{l}\mathrm{FEV}_{1}(\mathrm{ml}) \\
\text { Azlocillin }\end{array}$ & $1206(419)$ & $1760(862)$ & $45.9(<0.001)$ & \multirow{2}{*}{ NS } \\
\hline Carbenicillin & $1116(514)$ & $1619(871)$ & $45.1(<0.001)$ & \\
\hline $\begin{array}{l}\text { FVC (ml) } \\
\text { Azlocillin }\end{array}$ & $2045(824)$ & 2897 (1228) & $41.7(<0.001)$ & \multirow{2}{*}{ NS } \\
\hline Carbenicillin & $1810(503)$ & $2588(929)$ & $43.0(<0.02)$ & \\
\hline
\end{tabular}

*Analysis of covariance.

NS-not significant. 
Table 3 Mean serum and sputum concentrations ( $\mu \mathrm{g} / \mathrm{ml})$ of carbenicillin $(n=7)$ and azlocillin $(n=10)$ after an intravenous dose of $5 \mathrm{~g}$

\begin{tabular}{|c|c|c|c|c|c|}
\hline \multirow[t]{2}{*}{ Antibiotic } & \multirow[t]{2}{*}{ Sample } & \multicolumn{4}{|c|}{ Time after end of infusion } \\
\hline & & 0 & $15 \mathrm{~min}$ & $1 \mathrm{~h}$ & $2 h$ \\
\hline Azlocillin & $\begin{array}{l}\text { Serum } \\
\text { Sputum* }\end{array}$ & $\begin{array}{r}44 \cdot 3 \\
2 \cdot 2\end{array}$ & 629 & $3 \cdot 2$ & $3 \cdot 1$ \\
\hline Carbenicillin & $\begin{array}{l}\text { Serum } \\
\text { Sputum }\end{array}$ & $\begin{array}{r}12 \cdot 8 \\
4 \cdot 6\end{array}$ & 309 & 8.9 & $7 \cdot 5$ \\
\hline
\end{tabular}

${ }^{*}$ Detectable concentration in only five patients

eight patients were not available. One strain was very resistant to both azlocillin and carbenicillin (MIC $>400 \mu \mathrm{g} / \mathrm{ml}$ ) but sensitive to gentamicin. The MIC for carbenicillin for the other 11 strains ranged from 12.5 to $200 \mu \mathrm{g} / \mathrm{ml}, \mathrm{MBC}$ values being identical or one dilution greater. The MIC for azlocillin ranged from 1.6 to $12.5 \mu \mathrm{g} / \mathrm{ml}$; MBC values were four times greater in three strains but otherwise similar to the MIC.

In three patients the strains of $P$ aeruginosa isolated from the sputum before and after treatment were apparently identical. All three had received carbenicillin, and there was a fourfold rise in MIC. In two other cases different serotype strains were isolated in the pretreatment and post-treatment sputum samples.

\section{Discussion}

Azlocillin has a high in vitro activity against Gram negative organisms and against some Gram positive organisms, but it is relatively sensitive to the action of $\beta$ lactamases. Strains of $P$ aeruginosa sensitive to carbenicillin and gentamicin are sensitive to concentrations of azlocillin of $8 \mu \mathrm{g} / \mathrm{ml}$ or less, while most strains resistant to carbenicillin and gentamicin are susceptible to $32 \mu \mathrm{g} / \mathrm{ml}$ of azlocillin. The in vitro activity of azlocillin against $P$ aeruginosa is about eight times that of carbenicillin. ${ }^{10}$ Comparative killing curves for carbenicillin and azlocillin show that the latter is bactericidal at serum concentrations about eight times lower than is carbenicillin."

After an intravenous infusion of $5 \mathrm{~g}$ in adult patients with cystic fibrosis in the present study, azlocillin had a mean peak serum concentration of $629 \mu \mathrm{g} / \mathrm{ml}$ and trough concentration of $44 \mu \mathrm{g} / \mathrm{ml}$. These concentrations are similar to those reported in other studies both in patients with cystic fibrosis and in normal individuals. ${ }^{12-14}$

Sputum concentrations of both penicillins were very low by comparison with serum concentrations. Azlocillin was detectable in the sputum of only five out of 10 patients (range $2.5-13.8 \mu \mathrm{g} / \mathrm{ml}$ ); values of $1-38 \mu \mathrm{g} / \mathrm{ml}$ were reported in a study on children with cystic fibrosis by Malmborg et al. ${ }^{14}$ We have previously reported the poor sputum penetrations of carbenicillin and ticarcillin in adults with cystic fibrosis. ${ }^{15}$ Inactivation of antibiotics by $\beta$ lactamases or leucocyte enzymes in pus ${ }^{16}$ may reduce the concentrations measured in sputum in a bioassay, and these low values may reflect the very purulent nature of cystic sputum in cystic fibrosis. Equally low values for azlocillin were, however, obtained by Daikos $e^{a}{ }^{17}$ in a study of patients with other respiratory problems.

The MIC ranges of azlocillin and carbenicillin for $P$ aeruginosa from 12 patients with cystic fibrosis were similar to those reported for strains of pseudomonas from other patients with infections, ${ }^{18}$ and lower than the $\mathrm{MIC}_{50}$ values quoted by Prince and $\mathrm{Neu}$ for 62 isolates from patients with cystic fibrosis. ${ }^{19}$ The rise in the MIC of carbenicillin seen in three strains suggests the development of antibiotic resistance during the course of treatment, while the presence of different strains after treatment in two patients may be due to selective reduction of a previously dominant strain by the treatment. The therapeutic ratio of peak serum concentrations of azlocillin $(628.6 \mu \mathrm{g} / \mathrm{ml})$ to the highest MIC of azlocillin $(12.5 \mu \mathrm{g} / \mathrm{ml})$ was $50 \cdot 3$, the equivalent ratio for carbenicillin being $308 \cdot 9 / 200$-that is, $1 \cdot 6$. Azlocillin might therefore be expected to have far greater clinical efficacy in patients with pseudomonas bacteraemia. The therapeutic ratios in sputum, however, were very much lower- 0.26 for azlocillin and 0.05 for carbenicillin. Not surprisingly, there was no difference between the two antibiotics in the degree of clinical response in patients with cystic fibrosis, whose infections are localised to the bronchial tree. ${ }^{20}$ The high serum concentration of azlocillin may be due to a smaller volume of distribution and lesser penetration of tissues.

Side effects previously reported with carbenicillin include allergic reactions, haemorrhagic cystitis, defective platelet aggregation, and alterations in the responses to liver function tests. The infusion is very irritant to veins and this is particularly a problem in younger patients. Michalsen and Bergen ${ }^{21}$ reported that five out of nine patients with cystic fibrosis treated with azlocillin developed a rash, while Møller et al $^{22}$ noted that seven out of 20 patients having azlocillin developed systemic side effects with rashes, pyrexia, arthralgia, and lymphadenopathy. In this study no side effects of treatment were observed, and both penicillins were well tolerated.

Several open trials on the use of azlocillin for pseudomonas infections in cystic fibrosis have been 
reported. Carswell and Ward ${ }^{23}$ treated 15 children with azlocillin and tobramycin and noted objective improvement. Malmborg et al ${ }^{14}$ treated 18 patients with azlocillin and an aminoglycoside, achieving a good clinical response but not eradication of the organism. Michalsen and Bergen ${ }^{21}$ treated patients with azlocillin alone and observed a gradual increase in the MIC of azlocillin for $P$ aeruginosa; they therefore recommended its use with an aminoglycoside. One comparative study of carbenicillin, azlocillin, and piperacillin, all in combination with an aminoglycoside, has been reported from Denmark..$^{22}$ The eradication of pseudomonas from sputum was greatest in the carbenicillin treated group even though this antibiotic has a higher MIC than the other two. There was no difference between regimens in terms of pulmonary function.

There have been very few randomised controlled clinical trials of chemotherapy for pseudomonas infection in cystic fibrosis reported, and this is largely due to the unique features of this condition. The organism remains localised within the respiratory tract and bacteraemia is extremely rare, ${ }^{20}$ yet antibiotics are almost always given in the doses used for systemic infections. Once the organism is detected in the sputum of a particular patient it is rarely eradicated for any length of time, so that the bacteriological objective of sterilisation of the sputum specimen, attempted in most trials of chemotherapy, is not applicable to cystic fibrosis. ${ }^{3}$ The usual features of an infection, such as pyrexia and increases in white cell count, erythrocyte sedimentation rate, and acute phase proteins, may not be present in an acute on chronic exacerbation of cystic fibrosis pulmonary disease. It may also be very difficult to see new changes on a chest radiograph that is already severely abnormal. The progressive nature of the disease may make it difficult to use patients as their own controls in crossover studies. Most studies note that the severely ill patients do not respond to any form of treatment without attempting to define or exclude such patients. The severely ill patient is, of course, in need of effective chemotherapy, but there will come a time in any progressive disease when treatment will no longer have any effect. For the purpose of a comparative study of two treatments it would seem reasonable to exclude those patients who may not respond at all, and who may be the most inconvenienced by the additional tests and assessments needed for such a study. Many authors use clinical scoring systems such as that of Shwachman, ${ }^{24}$ but most of the features included in this system, such as nutritional state and signs such as clubbing and chest deformity, do not change in the short term.

The present study was designed as a randomised comparative trial, excluding severely ill patients. We have measured a clinical response, primarily in terms of respiratory function tests, and also included an assessment of patients' well being. As expected, there was no change in the bacteriological characteristics of the sputum. We have documented a significant and substantial improvement in respiratory function in patients with cystic fibrosis treated acutely with antipseudomonal antibiotics. Despite the difference in in vitro activity against pseudomonas of the two penicillins we compared, there was no difference in the degree of response. Neither penicillin penetrated sputum well, but azlocillin has the practical advantages of a low sodium content and a recommended eight hour dose interval. Before the advent of antipseudomonal antibiotics patients with cystic fibrosis were admitted to hospital for physiotherapy, with moderate improvement in respiratory function. The response to antibiotics was considered to be much greateralthough, regrettably, this was not documented in any formal way. At the time many clinicians thought that placebo controls might be unethical. Perhaps the time has now come for a placebo controlled trial to assess how much of the observed benefit of treatment is due to hospital care and physiotherapy alone.

Antibiotic assays and sensitivity tests were performed by $\mathrm{Mr} \mathrm{H}$ Wingfield, Mrs Maureen Chadwick, and Mr G Hutchinson, department of microbiology, Brompton Hospital. Miss M Rehahn advised on statistical analysis. Pseudomonas typing was performed at the Central Public Health Laboratory, Colindale, by courtesy of Dr TL Pitt. Miss S Hockley kindly prepared the manuscript. ARLP is supported by the Augustus and Frances Newman Foundation.

\section{References}

' Kulczycki LL, Murphy TM, Bellanti JA. Pseudomonas colonisation in cystic fibrosis. A study of 160 patients. JAMA 1978;240:30-4.

2 di Sant' Agnese PA, Davis PB. Cystic fibrosis in adults: 75 cases and a review of 232 cases in the literature. Am J Med 1979;66:121-32.

${ }^{3}$ Marks MI. The pathogenesis and treatment of pulmonary infections in patients with cystic fibrosis. $J$ Pediatr 1981;9:173-8.

${ }^{4}$ Hodson ME. Immunological features of cystic fibrosis. MD Thesis, Leeds University, 1977.

s Pitcher-Wilmott RW, Levinsky RJ, Gordon I, Turner MW, Matthew DJ. Pseudomonas infection, allergy and cystic fibrosis. Arch Dis Child 1982;57:582-6.

${ }^{6}$ Cotes JE. Lung function: assessment and application in medicine. 4th ed. Oxford: Blackwell Scientific Publications, 1979.

' Stokes EJ, Waterworth PM. Antibiotic sensitivity tests by 
the diffusion method. Association of Clinical Pathologists Broadsheet No 55. London: Association of Clinical Pathologists, 1972.

${ }^{8}$ Waterworth PM. Quantitative methods for bacterial sensitivity testing. In: Reeves DS, Phillips I, Williams JD, Wise $\mathbf{R}$, eds. Laboratory methods in antimicrobial chemotherapy. Edinburgh: Churchill Livingstone, 1978:31-40.

9 Perkins A. Statistics of plate assays. In: Reeves DS, Phillips I, Williams JD, Wise R, eds. Laboratory methods in antimicrobial chemotherapy. Edinburgh: Churchill Livingstone, 1978:155-67.

${ }^{10}$ Wise R, Gillett AP, Andrews JM, Bedford KA. Activity of azlocillin and mezlocillin against Gram negative organisms: comparison with other pencillins. Antimicrob Agents Chemother 1978;13:559-65.

" König HB, Metzger KG, Mürman RP, Offe HA, Schacht $P$, Shröck W. Azlocillin-a new penicillin against Pseudomonas aeruginosa and other Gram negative bacteria. Infection 1977;5:170-82.

12 Bergan T, Michalsen $\mathrm{H}$. Pharmacokinetics of azlocillin in children with cystic fibrosis. Arzneim Forsch 1979;29:1955-7.

${ }^{13}$ Lode H, Niestrath U, Koeppe P, Langmaack H. Azlocillin and mezlocillin: two new semisynthetic penicillins. Infection 1977;5:163-9.

${ }^{14}$ Malmborg AS, Alfredsson H, Kusoffsky E, Strandvik B. Azlocillin and gentamicin in respiratory tract infections with Pseudomonas aeruginosa in patients with cystic fibrosis. Scand J Infect Dis 1981;suppl 29:64-9.

15 Penketh ARL, Hodson ME, Batten JC. Ticarcillin compared with carbenicillin in the treatment of exacerbations of bronchopulmonary infection in cystic fibrosis.
Br J Dis Chest 1983;77:179-84.

${ }^{16}$ Barnes P, Waterworth PM. New cause of penicillin treatment failure. $\mathrm{Br}$ Med J 1977;i:991-3.

${ }^{17}$ Daikos GK, Giamarellou H, Hadjiipolydorou K, Kanellakopoulou K. Pseudomonas infections of the lung treated with azlocillin. Arzneim Forsch 1979;29:1976-8.

${ }^{18}$ Eykyn SJ. Azlocillin in the treatment of serious infection with Pseudomonas aeruginosa. J Antimicrob Chemother 1982;9:395-403.

${ }^{19}$ Prince AS, Neu HC. Activities of new beta-lactamase antibiotics against isolates of Pseudomonas aeruginosa from patients with cystic fibrosis. Antimicrob Agents Chemother 1981;20:545-6.

${ }^{20}$ McCarthy MM, Rourk MH, Spock A. Bacteraemia in patients with cystic fibrosis. Clin Pediatr 1980;19:746-8.

${ }^{21}$ Michalsen H, Bergen T. Azlocillin with and without an aminoglycoside against respiratory tract infections in children with cystic fibrosis. Scand J Infect Dis 1981;suppl 29:92-7.

${ }^{22}$ Møller NE, Riewerts Eriksen K, Feddersen C, et al. Chemotherapy against Pseudomonas aeruginosa in cystic fibrosis. A study of carbenicillin, azlocillin or pipercillin in combination with tobramycin. Eur $J$ Respir Dis 1982;63:130-9.

${ }^{23}$ Carswell $\mathrm{F}$, Ward CCL. High dose intravenous azlocillin and tobramycin in cystic fibrosis patients. $\mathrm{Br} J \mathrm{Clin}$ Pract 1981;symposium supplement 14:9.

${ }^{24}$ Shwachman H, Kulczycki LL. Long-term study of 105 patients with cystic fibrosis: studies made over a 14 year period. Am J Dis Child 1958;96:6-15. 